\title{
Primary osteosarcoma of breast
}

\author{
Sadaf Gull, ${ }^{1}$ Prashant Patil, ${ }^{2}$ Roy AJ Spence ${ }^{1}$ \\ 1Department of General Surgery, Belfast City Hospital, Belfast, UK; \\ ${ }^{2}$ Department of Surgery, Daisy Hill Hospital, Newry, UK
}

Correspondence to Sadaf Gull, drsadaf_92@hotmail.com

\section{Summary}

Primary osteosarcoma of breast is rare. The authors present a case of a 51-year-old female who was admitted with a large necrotising tumour involving the right breast. CT scan confirmed chest wall invasion along with a solitary lung metastasis. She underwent a primary mastectomy with chest wall reconstruction. Unfortunately 3 months later she developed local recurrence.

\section{BACKGROUND}

Primary osteosarcoma of the breast $(\mathrm{POB})$ is rare and fewer than 150 cases have been reported in the English language literature over the past 50 years. We present the case of one such patient.

POB represents less than $1 \%$ of breast tumours. ${ }^{1}$ Patients are usually diagnosed as 'primary carcinoma' of the breast and the diagnosis of osteosarcoma is made subsequently on histological examination. $\mathrm{POB}$ is a very aggressive tumour and is histologically indistinguishable from conventional osteosarcoma of bone and other extraskeletal sarcomas. Clinically, the lesion may present as a well-circumscribed lump (suspected as a fibroadenoma) or a rapidly growing tumour disfiguring the breast (raising the suspicion of a phylloides tumour). Mammography can be deceptively benign. Surgical treatment involves either wide local excision of lesion or a complete mastectomy. Axillary clearance is usually not indicated since spread is not via lymphatics and axillary node involvement is exceptional. ${ }^{2}$ Adjuvant chemotherapy and radiotherapy reduce the risk of local recurrence. Five-year survival is only $38 \%$. Metastases are most commonly to lung (80\%) bone $(20 \%)$ and liver $(20 \%) .{ }^{3}$ Size of the tumour is the most important prognostic factor along with number of mitoses, presence of stromal atypia and incomplete resection.

\section{CASE PRESENTATION}

A 51-year-old lady presented to casualty with history of lethargy, fever and weight loss for several weeks. Examination revealed a large $(20 \times 20 \mathrm{~cm})$ fungating tumour in her right breast (figure 1). The patient had been aware of the lump for 4 weeks. All inflammatory markers were raised and she was found to be anaemic. Initial imaging including chest $\mathrm{x}$-rays was normal. Blood cultures were taken which did not reveal any growth in $48 \mathrm{~h}$.

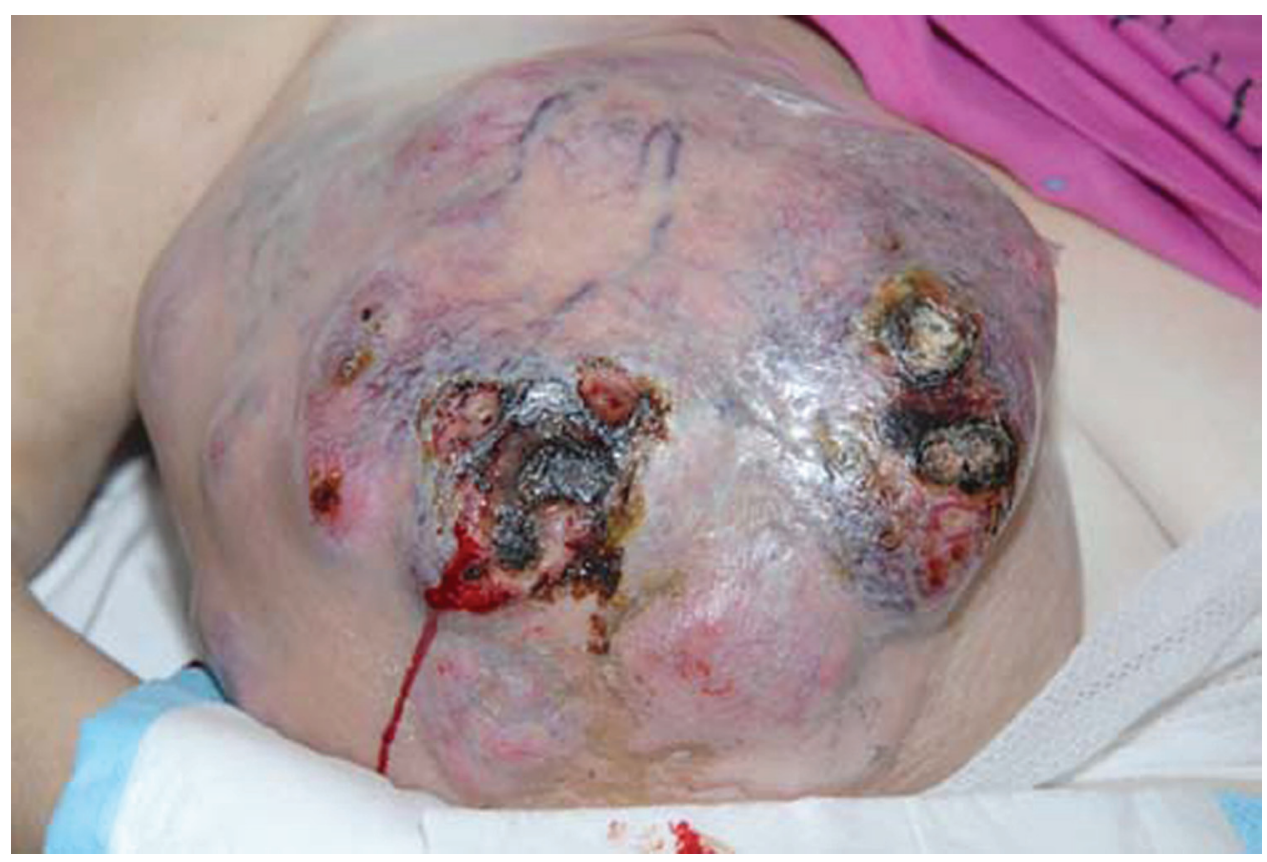

Figure 1 Osteosarcoma of right breast. 


\section{BMJ Case Reports}

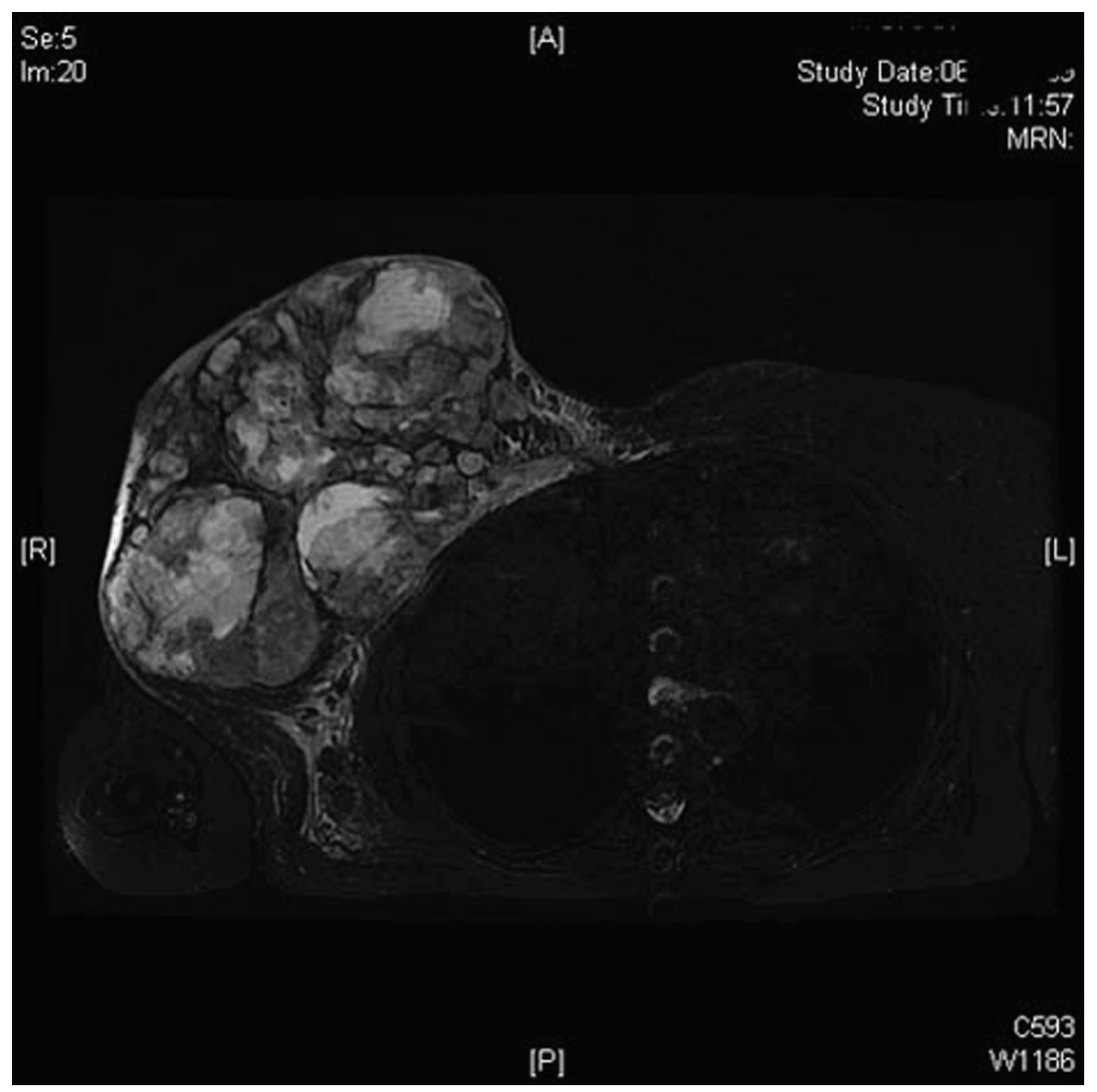

Figure 2 MRI showing multi-loculated tumour mass.

The symptoms were thought to be due to necrosis and haemmorrhage into the tumour.

The patient was transfused with packed red cells and was started on broad spectrum antibiotics.

CT scan and MRI revealed a large tumour (figure 2) involving the chest wall and a solitary nodule in the right lung. The core biopsy raised the suspicion of either phylloides sarcoma or primary sarcoma of breast. Her case was discussed at the lung and breast multidisciplinary team meetings. She was referred to plastic surgeons for radical mastectomy including chest wall excision and reconstruction.

\section{TREATMENT}

The patient underwent a simple mastectomy and at surgery the tumour was found to be free from the chest wall. The tumour weighed $4.8 \mathrm{~kg}$ and measured $25 \mathrm{~cm}$ $\times 14 \mathrm{~cm}$ with ulcerated skin. A few lymph nodes were identified and these were replaced with metastases. Immunohistochemistry results showed strong staining for mesenchymal markers vimentin and actin but was negative for desmin, CAM5.2, CK7 and CK1, no epithelial differentiation was seen, it was also negative for oestrogen and progesterone receptors. In the absence of any carcinoma and in view of above immunohistochemistry along with presence of mineralised matrix a diagnosis of primary osteosarcoma of breast was made.
The patient made a good recovery from her breast surgery and was referred to the thoracic surgeons for excision of the lung metastasis.

\section{OUTCOME AND FOLLOW-UP}

Unfortunately she developed local recurrence (figure 3) with widespread metastases (figure 4 ) and passed away 4 months later.

\section{DISCUSSION}

Extra-skeletal osteosarcomas are uncommon. The majority arise in the soft tissue of lower extremity. ${ }^{4}$ Their origin in a number of parenchymal organs has been documented. Mammary sarcomas are rare, representing less than 1\% of all primary breast malignancies. ${ }^{5}$ In comparison, bone producing spindle cell neoplasms with an epithelial origin, so called metaplastic (sarcomatoid) carcinomas, are more common. ${ }^{6} \mathrm{POB}$ is considered a disease of middle and old age in comparison to the younger age group of patients with skeletal osteosarcoma.

Many cases of breast osteosarcoma have been described in association with biphasic tumours such as phylloides and fibroadenoma, but only tumours fulfilling certain criteria are termed pure osteosarcoma. These criteria are exclusion of origin in bone, presence of neoplastic osteoid or bone, absence of an epithelial component and no association with 


\section{BMJ Case Reports}

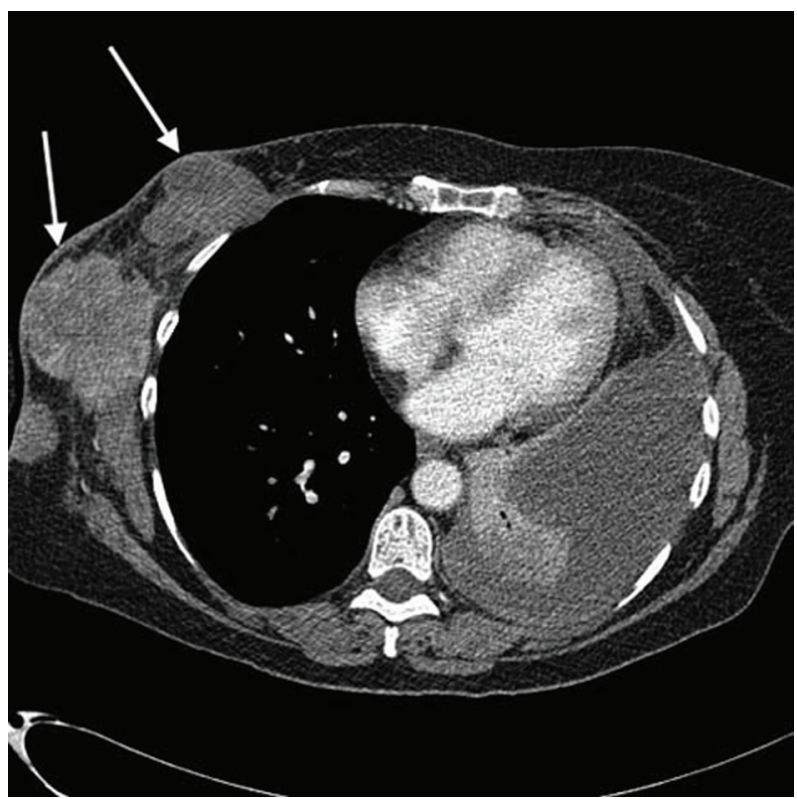

Figure 3 CT scan showing local recurrence (indicated by arrows).

a benign tumour. ${ }^{7}$ Our case fulfilled all the above criteria and was, therefore, a pure $\mathrm{POB}$. Immunohistochemistry also has a major role in diagnosis of $\mathrm{POB}$ and differentiating it from a phylloides tumour and metastatic disease, the investigation requires use of more than one epithelial marker including AE1/AE3, CK7, CAM5.2, EMA, the high molecular weight cytokeratin $34_{\square}$ E12(K903) MAC-387, KP1, S-100 protein, smooth muscle actin (SMA), vimentin, oestrogen and progesterone receptors. ${ }^{8}$ It is very important to keep in mind that area with cartilaginous differentiation in breast might be reactive focally to EMA. The tumour cells in POB usually exhibit S-100 protein, vimentin and SMA. ${ }^{8}$

This neoplasm is usually aggressive, characterised by early recurrence, as in our patient.

The histogenesis of $\mathrm{POB}$ is unknown but most of the sarcoid breast tumours are related to biphasic tumours. ${ }^{8}$ Origin from totipotent mesenchymal cells of the breast or transformation from pre-existing breast tumours has been suggested but this needs immunohistochemical proof.

The treatment of $\mathrm{POB}$ is complete excision of the tumour with adequate margins. It is debatable whether modified radical mastectomy should be done with axillary node dissection where there is clinical evidence of lymph node involvement. ${ }^{3}$ Although it is usually not indicated as spread to nodes is uncommon. Adjuvant chemotherapy is recommended and has shown to improve the survival rate dramatically (in some cases by $38 \%$ ) but limited data is available on the long term efficacy.

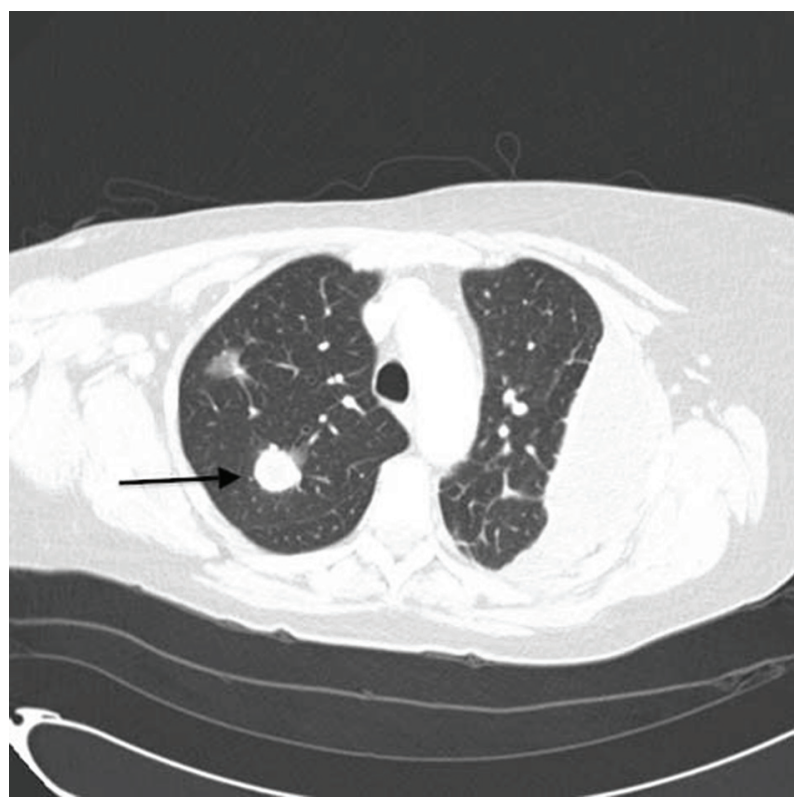

Figure 4 CT scan showing pulmonary metastases (arrow) and left pleural effusion.

Learning points

- Primary osteosarcomas of breast are rare and very aggressive tumour, hence a very high suspicion of index is needed to treat and diagnose them.

- Aggressive surgical excision should be considered as primary treatment.

Competing interests None.

Patient consent Obtained.

\section{REFERENCES}

1. Dragoumis D, Bimpa K, Assimaki A, et al. Case report on primary osteosarcoma of the breast. Singapore Med J 2008:49:315-17.

2. Saber B, Nawal A, Mohamed F, et al. Primary osteosarcoma of the breast: case report. Cases $\mathrm{J}$ 2008;1:80.

3. Khan S, Griffiths EA, Shah N, et al. Primary osteogenic sarcoma of the breast: A case report. Cases J 2008;1:148

4. Chung EB, Enzinger FM. Extraskeletal osteosarcoma. Cancer 1987; 60:1132-42.

5. Barnes L, Pietruszka M. Sarcomas of the breast: a clinicopathologic analysis of ten cases. Cancer 1977:40:1577-85.

6. Bahrami A, Ressetkova E, Ro J, et al. Primary osteosarcoma of the breast: report of 2 cases. Arch Pathol Lab Med 2007:131:792-5.

7. Murakami S, Isozaki H, Shou T, et al. Primary osteosarcoma of the breast. Pathol Int 2009;59:111-15

8. Silver SA, Tavassoli FA. Primary osteogenicsarcoma of the breast. A clinicopathological analysis of 50 cases. Am J Surg 1998; 22:25-33. 


\section{BMJ Case Reports}

This pdf has been created automatically from the final edited text and images.

Copyright 2011 BMJ Publishing Group. All rights reserved. For permission to reuse any of this content visit http://group.bmj.com/group/rights-licensing/permissions.

BMJ Case Report Fellows may re-use this article for personal use and teaching without any further permission.

Please cite this article as follows (you will need to access the article online to obtain the date of publication).

Gull S, Patil P, Spence RAJ. Primary osteosarcoma of breast. BMJ Case Reports 2011;10.1136/bcr.03.2011.4015, date of publication

Become a Fellow of BMJ Case Reports today and you can:

- Submit as many cases as you like

- Enjoy fast sympathetic peer review and rapid publication of accepted articles

- Access all the published articles

- Re-use any of the published material for personal use and teaching without further permission

For information on Institutional Fellowships contact consortiasales@bmjgroup.com

Visit casereports.bmj.com for more articles like this and to become a Fellow 